\title{
Extending the focus of management review quarterly: one year later
}

\author{
Joern Block ${ }^{1,2} \cdot$ Christian Fisch $^{1,2}$
}

Published online: 10 January 2019

○) Springer Nature Switzerland AG 2019

Dear readers of Management Review Quarterly,

We have been given the editorial responsibilities of MRQ about one year ago (first issue of Volume 68). Since then, we extended the journal's focus beyond systematic literature reviews and meta-analyses to also include bibliographic studies and replication studies. All four article types are tremendously important to pursue MRQ's aim to summarize and categorize knowledge in management and business research, aggregate important empirical research findings, and challenge existing knowledge.

We are confident that these four areas of focus will allow us to further develop MRQ into a strong niche journal and enable us to reach a unique and successful position in the landscape of business and management journals. Enabled by the extended focus, we saw a marked increase in interest for MRQ in 2018. Submission numbers increased by approximately $60 \%$ and MRQ's articles were downloaded 41,338, up from 26,339 in 2017. In 2018, we published 21 articles (including editorials and online first articles). MRQ's current acceptance rate is about $34 \%$.

To further shape our journal and guide potential contributors about our expectations, we published two editorials in 2018. The first editorial gives potential contributors guidance in crafting their literature review (Fisch and Block 2018). It points out six best-practices that are crucial for authors interested in submitting their literature review to MRQ. The second editorial (Block and Kuckertz 2018) describes what kind of replication studies MRQ is looking for. Specifically, it outlines seven principles that replication studies submitted to MRQ should follow.

Both editorials provide important guidance and serve as "must-reads" for authors interested in submitting a manuscript to MRQ. Importantly, they also separate MRQ from other journals by clearly communicating which manuscripts fit best with MRQ,

$\otimes$ Christian Fisch

cfisch@uni-trier.de

Joern Block

block@uni-tier.de

1 Faculty of Management, Trier University, Trier 54296, Germany

2 Erasmus School of Economics and Erasmus Institute of Man-agement (ERIM), Erasmus University Rotterdam, P.O. Box 1738, Rotterdam, DR 3000, The Netherlands 
thus facilitating and underlining the focused mission of MRQ. In the years to come, we will continue with this practice and work on further editorials communicating the unique demands, expectations, and features of articles suitable for MRQ. The focus of the next editorials will be on bibliographic studies and meta-analyses.

We would like to thank our readers, authors, reviewers, and members of the editorial board for their tremendous support. Reassured by the successful year 2018, we will continue with our mission to develop MRQ into a successful and focused niche journal.

If you have any feedback towards further improvement of the journal that you would like to share, please contact us at mrq@uni-trier.de. We also invite you to follow MRQ on Twitter (@MRQ_Journal).

\section{References}

Block J, Kuckertz A (2018) Seven principles of effective replication studies: strengthening the evidence base of management research. Manag Rev Q 68(4):355-359

Fisch C, Block J (2018) Six tips for your (systematic) literature review in business and management research. Manag Rev Q 68(2):103-106

Publisher's Note Springer Nature remains neutral with regard to jurisdictional claims in published maps and institutional affiliations. 